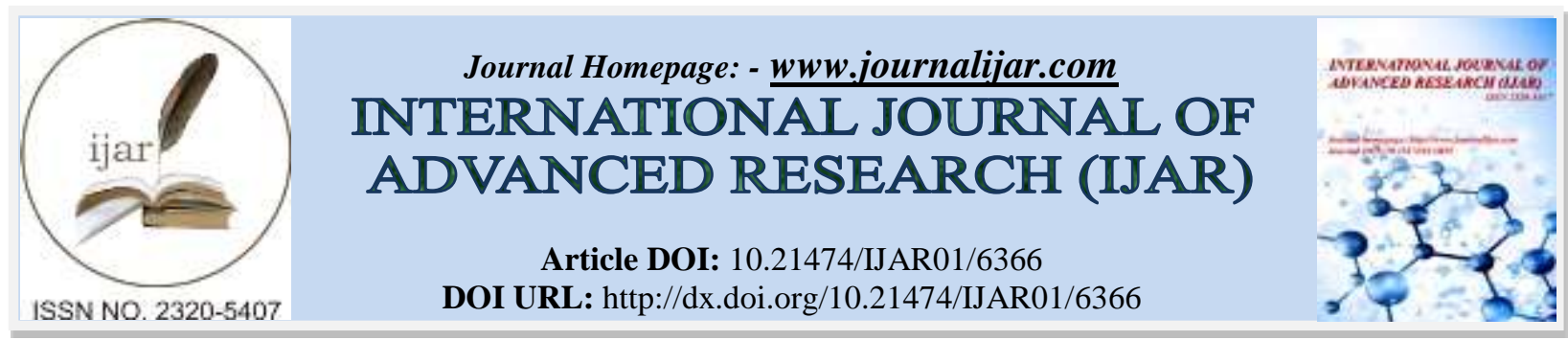

RESEARCH ARTICLE

\title{
USE OF GEORGIAN NON-TRADITIONAL AGRICULTURAL RESOURCES IN AGRICULTURE.
}

Eprikashvili L, Pirtskhalava N, Zautashvili M, Kordzakhia T, Dzagania M. and Tsintskaladze G. I.Javakhishvili Tbilisi State University; PetreMelikishvili Institute of Physical and Organic Chemistry, 31 Politkovskaya str., 0186, Tbilisi, Georgia.

\section{Manuscript Info}

Manuscript History

Received: 21 November 2017

Final Accepted: 23 December 2017

Published: January 2018

Key words:-

natural zeolite, humates, brown coal, nanomaterials, soil fertility.

\begin{abstract}
Economical effective complex fertilizers used for improving soil fertility can be produced in countries with suitable agricultural resources. The results of tests that were held on organo-mineral fertilizer, which consists of natural zeolite and brown coal of the Georgian origin are discussed in the article. The results obtained make it possible to consider the proposed substrate as an effective ameliorant providing long-term effect of the introduced fertilizer (prolongation effect), as well as preventing the washout of nutrients. The biometric indicators of plants grown on such a substrate are much higher than the control indexes. Further research in this direction will allow to change the technique of cultivation and upgrading of depleted grounds through the use of nanomaterials and substandard waste of the coal mining industry. Also it will improve the ecology of the environment and the quality of the final product.
\end{abstract}

Copy Right, IJAR, 2018,. All rights reserved.

\section{Introduction:-}

To successfully solve the problem of rational and effective use of soil resources in agriculture, a comprehensive, focused study of their agronomic characteristics and an assessment of their fertility is necessary [1]. By studying the state of soils it is possible to successfully regulate the processes occurring in them and thereby actively influence on the process of the soil fertility. It is important to pay special attention to the fact that substances introduced into the soil for plant nutrition are not harmful for humans. Otherwise plants should be able to transform these substances in a form, that is acceptable to humans. Therefore, it is necessary to consider the nature and the character of the substances used to charge the plants. In addition, the successful development of vegetable and horticultural crops largely depends on the conditions of their cultivation [2]. To support the plant at every stage of its development, to increase immunity and to strengthen the life processes of the embryo is an important strategic task. Nutrition of seeds with microelements and growth stimulants initiates metabolic processes in the grain, regulates hormonal balance, promotes the development of primary roots of the plant and their secondary growth in case of a stressful situation [3].

Recently, for improving physical and chemical properties and restoring natural fertility the introduction of unconventional natural resources (so-called agronomic ores) has been widely used in many countries [4].

Nitrogen fertilizers have the leading role in increasing the yield of agricultural crops. This is caused by the extremely important role of nitrogen in plant's life. Used nitrogen fertilizers have a significant flaw: their efficiency coefficient does not exceed $30-40 \%$, the rest is washed out into underground horizons. Potassium and nitrogen 
fertilizers which are easily soluble in water, are quickly washed out of the soil whereas phosphorus fertilizers, on the contrary, connect to calcium, magnesium, aluminum and iron ions present in the soil in an inert form that is inaccessible to plants [5]. Organic fertilizers, which, combined with other components, have a positive effect on all the major agrochemical indicators and functions of soils also play an important role in the reproduction of fertility [6]. A group of organic substances of natural origin, known as humic fertilizers [7] is distinguished among organic fertilizers. The efficiency of assimilation of all nutrients by the plant sharply increases in the presence of humic substances [8-10].

It is important to note that the interaction mechanism between humates and macroelements of mineral nutrition is specific for each of them. The assimilation of nitrogen proceeds along with intensification of metabolic processes. At the same time the negative processes of nitrate formation are slowing down. Assimilation of potassium is accelerated by a selective increase in the cell membrane permeability. As for phosphorus, the humates primarily associating ions of calcium, magnesium and aluminum, prevent the formation of insoluble phosphates. Thus, as the content of humates in the soil increases, the phosphorus is carried-over by the plant [11].

There are several approaches for using humates as a means of increasing soil fertility. This can be explained by the variety of actions of humic acids contained in them. Therefore, humates can be considered in different ways: as fertilizers themselves, as a component of organomineral fertilizers, as a means to improve the efficiency of mineral and organic fertilizers, as a sorbent regulating the flow of mineral substances into plants and also as a plant growth stimulant [12].

Initial materials for obtaining humic fertilizers are: manure, peat, coal oxidized in natural conditions and other organic substances of humus nature. The researchers drew attention to coal, as a raw materials source for producing organic fertilizers long time ago $[13,14]$. It turned out that only the so-called weathered coal, i.e. coal oxidized in natural conditions is suitable for this purpose. Such coals contain up to $70 \%$ organic matter, including flotation waste of $20-60 \%$. The content of $\mathrm{CaO}$ in them reaches $30-40 \%$ of the mineral part. They are good sorbents, which have an alkaline reaction $(\mathrm{pH}=7.3-7.6)$. Due to these properties, oxidized coals can be successfully used as organic fertilizers [15]. Studies on the use of oxidized coals as combined fertilizers that increase the soil humus in the cultivation of agricultural crops are of particular relevance.

The successful use of natural zeolites in agriculture should also be mentioned. The results of the studies [16, 17] confirm the great potential of using the soil reclamation means - clinoptilolite-containing tuffs which are most accessible in Georgia and the need to develop methods for microbiological, physical and chemical control over the state of soils when introducing this meliorant. Zeolites occupy one of the most significant places among nanomaterials in the nanobioindustry. The presence of a three-dimensional aluminosilicate oxygen frame, forming a system of cavities and channels in which alkaline, alkaline-earth cations and water molecules are located is common to all minerals of the group of zeolites. Cations and water molecules are weakly bound to the frame and can be partially or completely replaced (removed) by ion exchange and dehydration and reversibly, without destroying the zeolite frame. Zeolites ion exchange properties are determined by the chemical affinity of the ions with the crystalline structure of the zeolite. By the ion-exchange on zeolites it is possible to isolate ions, the extraction of which is very difficult using another method. The absorption capacity of zeolites is 30 times higher than that of ionexchange resins. Changes in the total exchange capacity of zeolite cations, depending on their shapes and the type of absorbed ions, are 1-5 milliequivalent per $1 \mathrm{~g}$ of mass. These values are much higher than the capacity of absorbing of cations by sod-podzol soil by sierozems ( 0.15 milliequivalent/g), gray forest soil ( 0.20 milliequivalent/g), leached and thick chernozems (0.5-0.65 milliequivalent/g) [18]. The introduction of zeolites into the soil gives a double benefit: ensuring the long-term effect of the introduced fertilizer (the effect of prolongation) and preventing the washout of nutrients.

The effectiveness of the joint introduction of zeolite and significantly lowered mineral and organic fertilizer norms into the soil have been established.

Clinoptilolites are especially precious types of zeolites. They are widespread in nature and are applied in agriculture. These minerals have exceptional properties due to the high content of free (amorphous) and therefore accessible for the plant silicon, which actively participates in the exchange of calcium, phosphorus, chlorine, fluorine, sodium, sulfur, aluminum, manganese, cobalt, and a few other elements. It protects the apical meristem of the growing zone of the plant from damage when it comes in contact with the soil and facilitates the movement of the root tip in the 
soil. Therefore, the optimization of silicon nutrition leads to an increase in the mass of the roots, their volume and the whole, actively absorbing surface [19].

Plants growing on soil enriched with zeolite form a higher quality and ecologically safe crop. There is a technology based on the use of zeolite, which allows us to obtain absolutely ecologically appropriate agricultural products. Saturated with an organic component, zeolite, when introduced into the soil, becomes a complex fertilizer of an extended duration. The effective impact of it continues for a number of years, depending on the characteristics of the soil and the way of farming. Crop products grown using such organic enriched zeolite are environmentally safe [20, 21].

The use of zeolites in agriculture is based on their ability to retain and regulate distribution of moisture and microelements, including those introduced into the soil together with fertilizers and pesticides. They reduce the washout from the soil of fertilizers and chemical means, which allows to sharply reduce the ecological load on the environment. Due to their porous structure, zeolites accumulate means of chemical protection and participate in the ion exchange process. This allows us to protect plants from fungal diseases, insects and rodents, to fight viruses and harmful bacteria that damage plants and reduce the number of treatments with pesticides, and, therefore, to reduce costs and reduce environmental damage for a long time [22, 23]. Fertilizer nutrients absorbed and persisted by zeolites are slowly, but effectively feeding plants. At the same time, zeolites serve as traps for heavy toxic metals, radionuclides that enter the soil together with inorganic fertilizers and chemicals. They are prolongators of mineral fertilizers and contribute to decrease of the doses of fertilizers and pesticides introduced into the soil by 2-4 times [24]. The unique properties of zeolites allow us to simultaneously solve the most important problems. Firstly, they allow to get increased yield of high-quality and environmentally safe products. Secondly, they contribute to the preservation and enhancement of soil fertility and the improvement of the environment as a whole. Thirdly, they allow us to save expenses and labor [25].

Adding inorganic materials including natural zeolites to organic fertilizers, in particular to hothouse soils, is one of the ways to improve the water-air and physical-chemical regimes of the soil and ultimately, to extend the life of the soil. Unlike the loosening organic additives used for these purposes especially on heavy loamy soils, inorganic materials are resistant to be degraded by microorganisms. At the same time, they can have a significant influence on the microbiological processes in the ground themselves, contributing to the development of useful microflora [26]. The ratio of organic and mineral components has a great important in creation of artificial organomineral substrates. Some researches [27] show that this ratio is a factor that largely determines the soil processes such as the mineralization of organic substance.

Italian scientists [28] have studied the sorption of humic acids on yellow Neapolitan zeolite tuffs.

The results of the studies showed that enrichment of zeolite with divalent cations increases the sorption ability of zeolite tuff to humic acids, whereas enrichment with monovalent cations reduces it. According to scientists, the sorption of humic acids on tuff should be considered as a complex phenomenon, arising as a compromise between the ability of cations to form stable bridges with organic substances and on the other hand, by specific selective sorption of the tuff itself.

Nowadays, the problem of creating new types of complex organo-mineral fertilizers with increased agroecological value and efficiency is very important. The use of complex fertilizers containing a complete set of both macro- and microelements will allow us to significantly increase the productivity of agricultural production and improve the quality of products [29].

The effectiveness of organo-zeolite fertilizer consisting of a mixture of grinded zeolite tuffs and coal waste has been studied in a number of works [30-34]. The decomposition of organic waste produces ammonium ions, which are adsorbed in zeolite tuffs [35]. When introducing such fertilizers into the soil ammonium ions are oxidized by soil microorganisms and a process of nitrification having effect on growth and quality of the plants takes place.

\section{Objectives and Methods:-}

In our previous work [36] a positive effect of the used Georgian non-traditional natural resources (zeolite + brown coal) on some biometric indicators of test culture (barley) was shown. In order to increase the agroecological value and prolongation ability of the action, zeolite tuff and brown coal were introduced in the substrate composition. 
The following substrates were used in the experiment:

1. Clopnotylolite tuff of Tedzami (Georgia). The content of the basic mineral (clinoptilolite) varies between $70-80 \%$. 2. Brown coal of Akhaltsikhe (Georgia) which belongs to the humus-sapropelite group and belongs to the class of thin brown coals [37].

A meadow-brown soil with a slightly alkaline reaction of the aqueous solution $(\mathrm{pH}=7.3-7.9)$ with a low content of humus (1.93-2.90\%) and which by granulometric composition, refers to heavy loam was used in the experiment. Five versions of the experiment were carried out in vegetation vessels. Each of them was repeated three times. "Alaverdi-1" barley sort was used as a testing plant.

Unlike the first experiment, slightly modified versions were chosen. In the first version, soil (object of comparison) was used as a standard; in the second version - soil $+\mathrm{N}_{60} \mathrm{P}_{75} \mathrm{~K}_{45}$ was used; in the third version the ground zeolite without soil adding was used; in the fourth version just like in the third, only grounded brown coal was used; in the fifth version the substrate was made by mixing soil with brown coal and zeolite. In all versions of the experiment, barley seeds with good sowing qualities $(98.5 \%)$ were used.

\section{Results and Discussion:-}

The effectiveness of prepared substrates was determined by some biometric indicators (BI) [36] of the experimental plants.

The germination and germination energy of seeds are the most important indexes of their sowing qualities. Seeds with good germination and high germination energy always give friendly and valuable sprouts. The germination of seeds is very important while it determines their appropriateness for sowing and the rate of their sowing. Determination of germination is one of the most important ways of seed quality assessment. In case of poor germination, thinned crops are obtained, which reduces the yield. Germination should approach to $100 \%$. The germination of seeds mean the amount $(\%)$ of normally germinated seeds in the test sample. The seed germination can be done in laboratory as well as in the field. Laboratory germination - the percentage normally germinated seed within 7-10 days in a test sample. The percentage of normally germinated seeds in the first 3-4 days determine the germination energy (amicability) of the seeds.

Simultaneously, while germinating they determine the germination energy. Under the energy of germination, which is a characteristic of the amicability of seed germination, is meant the amount (\%) of normally germinated seeds within a certain period of time. In addition, the relative values of these parameters and the amicability of seed germination were calculated.

The table shows the averaged biometric indexes of barley in the first, second and fifth variants of the substrate during five consecutive sowings. As seen from the table the highest values were obtained on the fifth version of the substrate. In the case of the second variant where the soil is enriched with standard fertilizer $\mathrm{N}_{60} \mathrm{P}_{75} \mathrm{~K}_{45}$, the biometric indexes of the plant are higher than the ones during the control (pure soil). They begin to decrease consistently with increasing sowing multiplicity $(2 \rightarrow 5)$. In the $3^{\text {rd }}$ and $4^{\text {th }}$ variants of the substrate where only zeolite and brown coal are used, the biometric indexes of the plant are consistently improved with increasing sowing multiplicity $(2 \rightarrow 5)$. In the $5^{\text {th }}$ variant of the substrate (soil + zeolite + brown coal) of the plant (BI) increase intensively after sowing by increasing the sowing multiplicity $(2 \rightarrow 4)$.

Table:- Impact of substrate on seed biometric parameters of barley

\begin{tabular}{|l|l|l|l|l|}
\hline Type of substrate & \multirow{2}{*}{ Sowing } & Type substrate & \multicolumn{2}{|l|}{} \\
\cline { 2 - 5 } & & Soil & Soil-NPK & Soil-brown coal-zeolite \\
\hline \multirow{4}{*}{ Germination energy } & $1^{\text {st }}$ sowing & 70 & 80 & 46 \\
\cline { 2 - 5 } & $2^{\text {nd }}$ sowing & 66 & 36 & 60 \\
\cline { 2 - 5 } & $3^{\text {rd }}$ sowing & 40 & 35 & 84 \\
\cline { 2 - 5 } & $4^{\text {th }}$ sowing & 34 & 42 & 86 \\
\cline { 2 - 5 } & $5^{\text {th }}$ sowing & 20 & 30 & 64 \\
\hline \multirow{3}{*}{$\begin{array}{l}\text { Relative value of } \\
\text { germination energy }\end{array}$} & $1^{\text {st }}$ sowing & - & 3.0 & 0.9 \\
\cline { 2 - 5 } & $2^{\text {nd }}$ sowing & - & -0.1 & 0.5 \\
\cline { 2 - 5 } & $3^{\text {rd }}$ sowing & - & -0.5 & 0.31 \\
\hline
\end{tabular}




\begin{tabular}{|c|c|c|c|c|}
\hline & $4^{\text {th }}$ sowing & - & -0.4 & 0.24 \\
\hline & $5^{\text {th }}$ sowing & - & -0.2 & 0.18 \\
\hline \multirow[t]{5}{*}{ Germination } & $1^{\text {st }}$ sowing & 76 & 92 & 50 \\
\hline & $2^{\text {nd }}$ sowing & 78 & 42 & 68 \\
\hline & $3^{\text {rd }}$ sowing & 46 & 39 & 90 \\
\hline & $4^{\text {th }}$ sowing & 50 & 47 & 98 \\
\hline & $5^{\text {th }}$ sowing & 36 & 40 & 86 \\
\hline \multirow{5}{*}{$\begin{array}{l}\text { Relative value of seed } \\
\text { germination }\end{array}$} & $1^{\text {st }}$ sowing & - & 1.6 & 0.68 \\
\hline & $2^{\text {nd }}$ sowing & - & -0.08 & 0.78 \\
\hline & $3^{\text {rd }}$ sowing & - & -0.5 & 0.97 \\
\hline & $4^{\text {th }}$ sowing & - & -0.4 & 0.46 \\
\hline & $5^{\text {th }}$ sowing & - & -0.2 & 0.23 \\
\hline \multirow{5}{*}{$\begin{array}{l}\text { Relative size of height } \\
\text { of sprout }\end{array}$} & $1^{\text {st }}$ sowing & - & 0.03 & 0.01 \\
\hline & $2^{\text {nd }}$ sowing & - & 0.002 & 0.03 \\
\hline & $3^{\text {rd }}$ sowing & - & -0.06 & 0.04 \\
\hline & $4^{\text {th }}$ sowing & - & -0.04 & 0.07 \\
\hline & $5^{\text {th }}$ sowing & - & -0.02 & 0.08 \\
\hline \multirow[t]{5}{*}{ Rate of germination } & $1^{\text {st }}$ sowing & 22 & 23.0 & 23.2 \\
\hline & $2^{\text {nd }}$ sowing & 19 & 23.1 & 19.2 \\
\hline & $3^{\text {rd }}$ sowing & 18 & 21.0 & 19.3 \\
\hline & $4^{\text {th }}$ sowing & 20 & 19.5 & 22.8 \\
\hline & $5^{\text {th }}$ sowing & 27 & 17.9 & 21.0 \\
\hline \multirow[t]{5}{*}{ Intergrowth } & $1^{\text {st }}$ sowing & 4.4 & 5.0 & 3.3 \\
\hline & $2^{\text {nd }}$ sowing & 4.7 & 3.0 & 4.3 \\
\hline & $3^{\text {rd }}$ sowing & 5.4 & 2.4 & 6.2 \\
\hline & $4^{\text {th }}$ sowing & 2.4 & 2.0 & 9.0 \\
\hline & $5^{\text {th }}$ sowing & 1.4 & 1.8 & 4.6 \\
\hline
\end{tabular}

By the fifth time sowing, the substrate starts to run low in nutrient components and the BI decrease. The prolonged effect of this substrate is tracked to the fifth time sowing, whereas in the first and second variant, these values decrease.

The diagrams show the changes in biometric indexes on different samples in relation to the sowing multiplicity. In each separate case the results show the positive influence of pure natural zeolite and brown coal. The greatest increase in germination and the barley germination energy is observed when using a combined substrate: soil + zeolite + coal.

Diagram: Change of a biometric parameters of a plant (\%). 

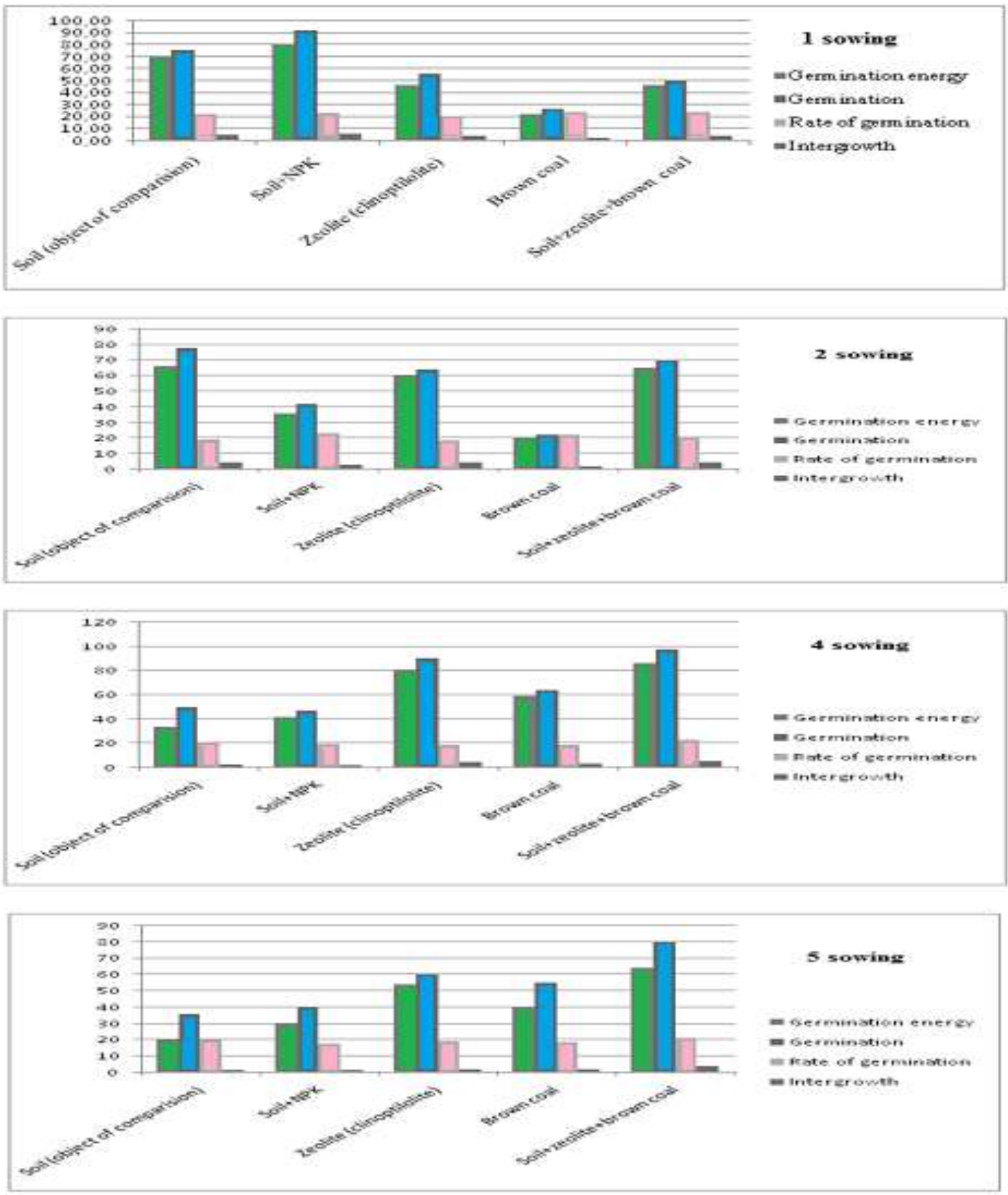

The picture shows the germination of barley on various substrates. The figure also clearly shows the difference in the growth of barley grown on the researched substrates. On the fifth substrate (soil + zeolite + coal) a more intensive development occurs for both, over the ground part of the plant and the root system. 


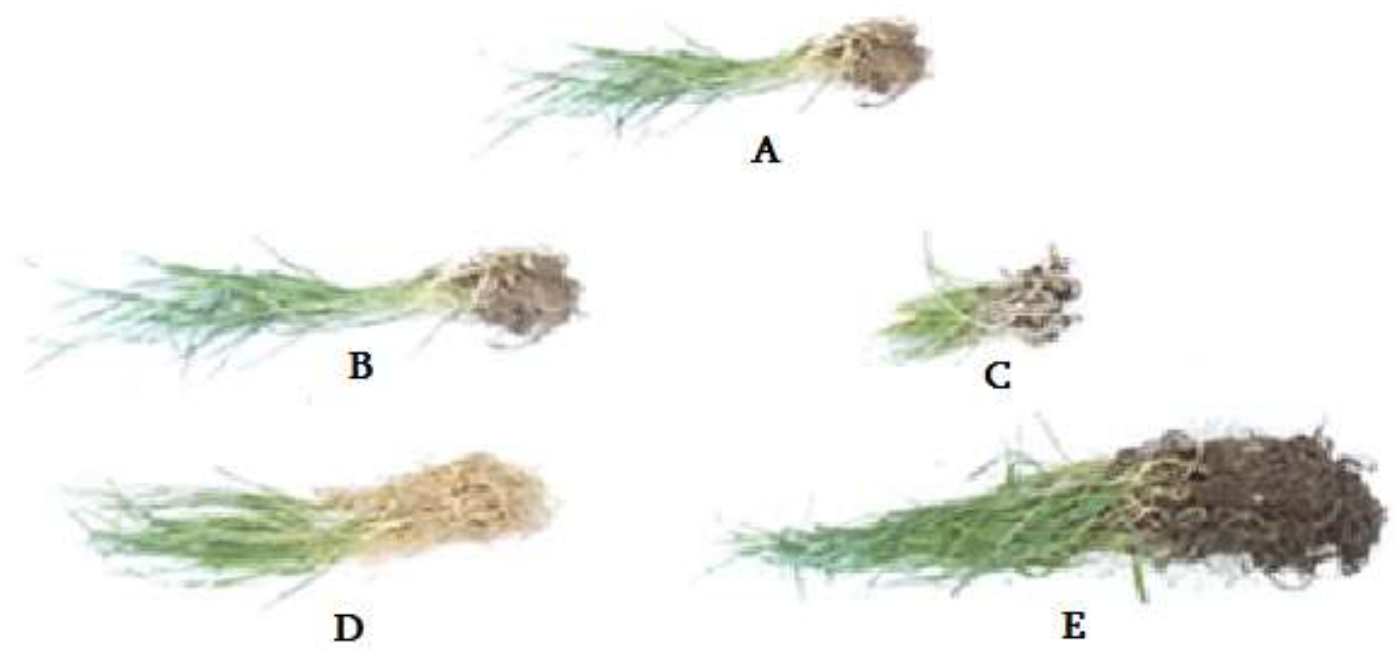

\section{Conclusion:-}

According to the obtained results, we can conclude that the combined use of natural zeolite and brown coal positively affects the productivity of the soil. Apart from that, such substrate is characterized by prolonged action (3, 4 sowings), whereas in the soil $+\mathrm{N}_{60} \mathrm{P}_{75} \mathrm{~K}_{45}$ variant the productivity of the soil decreases by increasing sowing multiplicity. Based on the obtained data, it seems prospective to carry out further researches for a more detailed study of the effect of the proposed organo-zeolite fertilizer on changes in soil productivity.

\section{References:-}

1. M.K.Gamisonia, T.G.Andronikashvili, A.V.Rusadze Study of the effect of clinoptilolite-containing tuffs on the physicochemical properties and biological activity of acid soils in humid subtropics. The use of clinoptilolitecontaining tuffs in plant growing. Metzniereba, Tbilisi, 1988, 85-116. (in Russian).

2. L. Burton, De Vere and Elmer L. Cooper. Agriscience Thomson Press, USA, 2005, 803.

3. V. Egorov //www.Agro-archive.ru /pochvovedenie/, The Physio-logical Role of the Most Impotant Elements Found in the Soil in the Life of Plants, 2015 (in Russian).

4. O.Y.Zardalishvili, T.T.Urushadze, M.O.Zardalishvili. Local ores of Georgia and prospeqts of their use for fertilization of agricultural crops. J.Ann. Agrar. Sci. 10(4), 2012, 57-61.

5. Cr.Ya Rinkins, V.F.Hollendorf. A Balanced of Plant Macro- and Micrometriens. Zinate, Riga, 1982 (in Russian).

6. A.Putkaradze, Influence of soil and organic fertilizer treatment differences on soil humus balance and crop yields. Proceedings of the St. Petersburg State University. (18), 2010, 79-81 (in Russian)

7. Y.Chen, C.E.Clapp, H.Magen, V.W.Cline. Simulation of Plant Growth by Humic Substances: Effect of iron Availability. Understanding Humic Substances. Advanced Methods, Properties and Applications EDS E. Ghabbour, G.Davies. Cambridge, 1990, 150.

8. I.V.Perminova, D.M.Zhilin, "Humic substances in contact of green chemistry, coll. articles Green chemistry in Russia. Moscow, 2004, 146-162. (in Russian).

9. A.I.Eskov, M.N.Novikov Problems of production and use of organic fertilizers. Agrochemical Herald. 4, 1998, 29-32. (in Russian).

10. B.V.Levin, S.A.Ozerov, G.A.Garmash, N.V.Latina, N.Yu.Garmash. Increase in agrochemical efficiency of complex phosphorus-containing fertilizers due to a humanitarian additive. Plant nutrition, 2, 2015, 2-8.(in Russian).

11. J.J.Schröder, A.L.Smit, D. Cordell, A.Rosemarin. Improved phosphorus use efficiency in agriculture: A key requirement for its sustainable use. Chemosphere, (84), 2011, 822-831.

12. L.V.Kvartsova et al. Influence of physiologically active humic substances on soil microorganisms. Humic fertilizers: theory and practice of their application. Dnepropetrovsk,1980. (in Russian).

13. Kh.A.Iskhakov. Brown coal as a complex fertilizer. Bulletin of the Kuzbass State Technical University, 5, 1998, 69-71. (in Russian).

14. D.S.Orlov. Humus acids of soils and general theory of humification.MGU, Moscow, 1990, 325. (in Russian). 
15. P.J.Leggo. Enhancing the Growth of Plants on Coal Waste using a Biological Fertilizer. International journal of Environment and Resource (IJER), 2, 2013,.59-66.

16. T.G. Andronikashvili, T.F.Urushadze, L.G.Eprikashvili Zeolite-containing substrates a new way from plant growing in plant production. J. Ann. Agrar. Sci. 7, 2009, 14-45. (in Russian).

17. J.A.Febles, G.S.Nuniz. Natural zeolite in the industry of fertilizers - agronomic results. Zeolite-2010, 8-th International Conference of the Occurrence, Properties and Utilization of Natural Zeolites,Sofia,Bulgaria, 2010.

18. B.Loboda. A Tareyev Zeolites - a new application of the old mineral. Science and Life, 10, 2017. (in Russian).

19. Z.P.Seredin.a Agroecological aspects of the use of zeolites as a sorbing-type soil improver and potassium source for plants. Proceedings of Tomsk Polytechnic University, 3, 2003, 306, (in Russian).

20. L.Deligiani, D.Petounis, M.Voulgari. Clinoptilolite in agricultural applications. Zeolite-2010,8-th International Conference of the Occurrence, Properties and Utilization of Natural Zeolites, Sofia, Bulgaria, 2010.

21. Ming D., Allen E. Use of natural zeolites in agronomy, horticulture and environmental soil remediation Reviews in mineralogy and geochemistry. Mineral Soc. Am. 45, 2001, 619-54.

22. Alberto C. de Campos Bernardi, Patricia Peronti Anchso Oliviera, Marisa B.de Melo Monte B, Fernando Souza-Barros. Brazilian sedimentary zeolite use in agriculture. Mikroporous and mesoporous materials, 167, 2013, 16.

23. P.Misaelides. Application of natural zeolites in environmental remediation. Microporous and Macroporous Materials, 144, 2011, 15-18.

24. E.Nikolaeva. Benefits of zeolite: 9 reasons "for" and not one "against" //www.ssad.lv/index.php/аксиомы\%20 truck farmers

25. O.Konusova, V. D.Perfilyeva. Effect of zeolite on some indicators of the biological activity of peat and peat substrates. Physico-chemical and methodological-biological properties of natural zeolites, Novosibirsk, 1990, 136-143. (in Russian).

26. A.Kocak, N.Deveer, F.A.Novruzova. Organo-mineral fertilizers from low grade lighites deposited aroung konya and their effect on agricultural production., J. Chemical Problems, 4, 2003, 53-55.

27. S.Capasso, S.Salvestrini, E.Coppola, A.Buandonno. Sorption of humic acid on zeolitic tuff: a preliminary investigation//https://doi.org/10.1016/j.clay, 2004.

28. T.Andronikashvili, T.Urushadze, T.Kordzakhia, L.Eprikashvili. New fertilizers of prolonged action on the basis of natular zeoites. J. Ann. Agrar. Sci. 8, (3), 2010, 42-68.

29. P.J.Leggo. The Organo-Zeolitic-Soil System: A new Approach to Plant Nutrition. Conference Paper, WSEAS, Cambridge, 2, 2017.

30. P.J.Leggo. The Efficacy of the Organo-Zeolitic Bio-fertilizer. Agroteqnology, 4, 1, 2015.

31. E.Filcheva, T.Popova, K.Chakalov, K.Dimitrov. Organic carbon and humic substances in zeolite amended clay soil, in the region of Maritza-Iztok JSC-coal mine complex. Zeolite-2010, 8-th International Conference of the Occurrence, Properties and Utilization of Natural Zeolites, Sofia, Bulgaria, 2010.

32. P.J.Leggo, B.Ledesert, G.Christie. The role of clinoptilolite in organo-zeolitic-soil systems used for phitoremediation. Science of the Total Environment, 363, 2006, 1-10.

33. P.J.Leggo. An investigation of plant growth in an organo-zeolitic and its ecological significance. Plant and Soil, 21, 2000, 135-146.

34. G.Tsintskaladze, L.Eprikashvili, N.Mumladze, V.Gabunia, T.Sharashenidze, M.Zautashvili, T.Kordzakhia, T.Shatakishvili Nitrogenous zeolite nanomaterial and the possibility of its application in agriculture. J. Ann. Agrar. Sci., 15, 2017, 365-369.

35. L.Epriкаshvili, M.Zautashvili, T.Kordzakhia, N.Pirtskhalava, M.Dzagania, I.Rubashvili, V.Tsitsishvili. Intensification of bioproductivity of agricultural cultures by adding natural zeolites and brown coals into soils. J. Ann. Agrar. Sci., 30, 2016, 1-5.

36. L.Eprikashvili, V.Tsitsishvili M.Zautashvili, T.Kordzakhia, M.Dzagania, N.Pirtskhalava Influence of the Soilfree Substrate on the biometric parameters of bean and barley germination. Bulletin of Georgian National a Academy of s Sciences, 9, 1, 2015, 139-144. 